\title{
Dynamic Relative Standards versus Emission Taxes in a Putty-Clay Model
}

Alejandro Caparrós, Richard E. Just, David Zilberman

\begin{abstract}
The paper derives the dynamics of pollution taxes and relative standards - which set bounds on emissions per unit of output—and the resulting optimal replacement of capital goods in a vintage model under the putty-clay assumption. Comparing policies that are constrained by the same aggregate pollution target level, the productive life of capital is longer under dynamic relative standards, as the variable cost of pollution imposed on aging capital is lower. As a result, the absolute level of output from the industry is generally higher under dynamic relative standards than under taxes. The results also show, under reasonable assumptions, that the pollution goal will be achieved using cleaner technologies under dynamic relative standards. These results can explain, from a political economy perspective, the prevalence of dynamic relative standards in regulations.
\end{abstract}

JEL Codes: H21, Q53, Q55

Keywords: Dynamic relative standards, Emission taxes, Generation performance standards, Political economy, Putty-clay, Vintage

WHEN COMPARING COMMAND and control approaches to pollution control to market-based instruments, economists tend to prefer market-based instruments because of their efficiency (see Requate [2005] for a survey of the literature). Neverthe-

Alejandro Caparrós (corresponding author) is at Consejo Superior de Investigaciones Cientificas (CSIC), Institute for Public Goods and Policies (IPP), Albasanz 26, 28037 Madrid, Spain (alejandro.caparros@csic.es). Richard E. Just is at the Department of Agricultural and Resource Economics, University of Maryland, College Park (rjust@arec.umd.edu). David Zilberman is at the Department of Agricultural and Resource Economics and Giannini Foundation of Agricultural Economics, University of California at Berkeley, Berkeley, CA 94720-3310, USA (zilber11@berkeley.edu). We thank coeditor Stephen Holland and two anonymous referees for constructive comments. Research leading to this article was paid by the USDAFAS-TASC_CDPB grant on methyl bromide alternatives. Alejandro Caparrós acknowledges financial support from the Spanish Ministry of Economy and Competitiveness (project ECO2012-35432). The usual disclaimer applies.

Received November 24, 2013; Accepted March 6, 2015; Published online April 9, 2015.

JAERE, volume 2, number 2. (C) 2015 by The Association of Environmental and Resource Economists. All rights reserved. 2333-5955/2015/0202-0004\$10.00 http://dx.doi.org/10.1086/681599 
less, command and control instruments remain very popular among policy makers, and there are few convincing reasons for this popularity (see, however, Buchanan and Tullock 1975; Berck and Helfand 2005).

Instruments of command and control can be classified into three categories: technological standards (the regulator prescribes that the firms adopt the best available technology), emission standards (firms are constrained by an absolute upper emissions level per unit of time), and relative standards (where firms face a cap on the ratio of emissions per output). As Requate (2005) points out, the latter standard is the most commonly used. Furthermore, in most cases, standards are set as dynamic relative standards (DRS), also known as dynamic generation performance standards, because they tend to become more stringent over time.

For example, European emission standards define the acceptable limits for exhaust emissions from most diesel vehicle types, including cars, trucks, trains, and nonroad diesel machines. The emission standards are defined in a series of European Union directives that impose increasingly stringent standards ${ }^{1}$ Currently, emissions for various types of pollutants, such as nitrogen oxides, particulate matter, or carbon monoxide, are regulated. For each diesel motor and moment in time, different standards apply, and noncompliant diesel motors cannot be sold in the EU. However, no specific technologies are mandated to meet these standards.

The United States has also favored standards since environmental legislation started in the late 1960s and the 1970s (see Stavins [2006] for a review of US policies where standards vary for different generations). The Clean Air Act, introduced in 1970, and the Corporate Average Fuel Economy (CAFE), enacted in 1975, are two prime examples (Berck and Helfand 2005). The former dictates the minimum level of air quality nationwide for six so-called criteria pollutants (the New

1. The EU regulation for nonroad diesels was introduced in two stages: Stage I, implemented in 1999, and Stage II, implemented from 2001 to 2004, depending on the engine power output. The equipment covered by the standard includes industrial drilling rigs, compressors, construction wheel loaders, bulldozers, nonroad trucks, highway excavators, forklift trucks, road maintenance equipment, snow plows, ground support equipment in airports, aerial lifts, and mobile cranes. Agricultural and forestry tractors have the same emission standards but different implementation dates (Directive 2000/25/EC). Stage III/IV emission standards for nonroad engines were adopted in 2004 (Directive 2004/26/EC) and for agricultural and forestry tractors in 2005 (Directive 2005/13/EC). Stage III standards were phased in from 2006 to 2013, and Stage IV in 2014. The Stage III/IV standards, in addition to the engine categories regulated by Stage I/II, also cover railroad locomotive engines and marine engines used for inland waterway vessels. For light motor vehicles, Euro 1 was introduced in 1992, Euro 2 in 1996, Euro 3 in 2000, Euro 4 in 2006, and Euro 5 in 2011, with Euro 6 scheduled to enter into force in 2015. Nevertheless, cars are the least relevant example for our paper, as we are dealing with manufacturer choices. 
Source Performance Standards [NSPS] developed under this legislation are more stringent for new plants than for existing plants and are occasionally reevaluated; see Heutel 2011). ${ }^{2}$ CAFE aims at improving the average fuel economy of cars and light trucks and has also become more stringent over time. The regulation of water quality (starting with the Water Quality Act of 1965) is yet another example in which relative standards have become more stringent over time. Finally, low carbon fuel standards have been intensively debated in the United States in recent years, and these standards are expected to evolve over time (see Huang et al. [2012] for a focus on biofuels and Holland, Hughes, and Knittel [2009] for a more general analysis).

All these examples show that DRS are a popular tool for regulating pollution. In each case the specific context of the application determines the details of the dynamic standard. Nevertheless, as we are interested in a general analysis we focus on the most basic form of this standard (see the details below).

Regarding the modeling framework, the putty-clay approach used in this paper is characterized by a variable capital-labor ratio at the moment that investment occurs (putty) and a fixed capital-labor ratio thereafter (clay). ${ }^{3}$ It requires capital goods to be nonmalleable once they are constructed; namely, it assumes that technological progress takes the form of a flow of new ideas for the construction of investments, but the modification of existing investment is not feasible (Bliss 1968, 2005). As the previous examples have shown, this assumption is also implicit in DRS because the regulator only imposes more stringent standards to new vintages, while old vintages can continue to operate under previous standards.

Although there are many papers that attempt to rank environmental policy instruments (Baumol and Oates 1974; Weitzman 1974; Requate and Unold 2003), relatively few have focused on standards (Harford 1978; Hochman and Zilberman 1978; Harford and Ogura 1983; Helfand 1991; Eber 1998; Montero 2002; Mohr 2006; Lahiri and Ono 2007; Fullerton and Heutel 2010; Hamilton and Requate 2012; Holland 2012). Most of the literature comparing command and control and market-based instruments has been done either in a static framework or in a dynamic framework focused on the timing of the regulator-pollutant game.

An exception is Stokey (1998), where a standard for the whole economy is compared to taxes (the main motivation is to compare alternative climate change policies).

2. The NSPS apply to new, modified, and reconstructed facilities in specific source categories such as manufacturers of glass, cement, rubber tires, and wool fiberglass. The NSPS are developed and implemented by the Environmental Protection Agency and are delegated to the states.

3. This approach was originally proposed as a compromise to overcome some of the limitations of capital theory highlighted in the "Cambridge controversy" (see Cohen and Harcourt 2003; Bliss 2005). 
Stokey analyzed optimal pollution control policy using different models and assuming a social planner interested in maximizing the utility of the representative household. Using a Ramsey-type model, she shows that along the equilibrium path optimal emissions decrease exponentially and, using a similar Cobb-Douglas function to the one introduced below, that in the centralized economy standards decrease exponentially and taxes increase exponentially. Stokey shows that implementation of the optimal policy in a decentralized economy is only possible through taxes, thus confirming the result already discussed in Johansen (1965). Nevertheless, it is relevant to investigate possible advantages of DRS as they are frequently used.

Wing, Ellerman, and Song (2006) present an interesting dynamic macro analysis of intensity-based caps in the context of climate change. Their analysis emphasizes the role of uncertainty, instead of the heterogeneity represented by vintages, as our analysis does. ${ }^{4}$

On the other hand, the literature focused on pollution control and vintages has not addressed the issue of standards versus market instruments. This literature has typically focused on the behavior of a firm under an environmental constraint (an absolute maximum level of pollution in Boucekkine, Hritonenko, and Yatsenko [2008]), on the analysis of pollution taxes or R\&D subsidies in a general equilibrium framework (Hart 2004; Ricci 2007; Azomahou, Boucekkine, and Nguyen-Van 2009) or on the impact of heterogeneous producers on optimal taxes (Xabadia, Goetz, and Zilberman 2006).

Finally, Smulders and Zemel (2011) analyze the impact of carbon taxes on energy transitions but do not compare them with standards. In addition, their model, similar to Farzin, Huisman, and Kort (1998) or Goeschl and Perino (2007), focuses on a complete technological switch from one technology to another, while ours allows continuous and gradual technological transition and improvement, accommodating both adoption and adaptation processes (Zilberman, Zhao, and Heiman 2012).

Thus, the existing literature adds little to the questions of which pollution control method is preferred in a setting with vintage-differentiated production and policies, which method induces faster adoption of new and cleaner technologies in this context, or under which method vintages remain in operation for a longer period of time. This last issue, which can only be answered through an explicit modeling of the scrapping time of different environmental policies, is of the utmost importance when dealing with assets with long investment periods.

4. The authors analyze the relative attractiveness of the two instruments under two criteria: (i) the minimization of the difference between the actual level and the initial expectation of abatement associated with a one-shot emission target and (ii) the minimization of the variance of abatement due to fluctuations in emissions and GDP over time. 
This paper focuses on cases where emissions depend on manufacturer choices (not on consumer choices) and on an industry-wide analysis because usually standards do not apply to the entire economy (Jung, Krutilla, and Boyd 1996; in fact, all the examples discussed above apply to one sector or one type of machinery). Within this context, this paper seeks to answer the following question: Assume that a government has decided to keep pollution below a certain level (a pragmatic policy approach emphasized by Baumol and Oates [1974] in their analysis of cost-effective policies), ${ }^{5}$ then, what are the implications for firms, or for an industry, of achieving this goal using taxes or DRS? ${ }^{6}$

The paper shows that a constant pollution target rate can be attained by increasing the pollution tax over time at a rate dependent on production function elasticities, the rate of technical change, the rate of growth in wages, the demand elasticity, and the rate of growth in demand. In addition, results show that the same constant pollution rate can be attained by imposing a pollution/production standard that is tightened over time at a rate depending on the same factors. While pollution taxes are the most efficient way to attain the same pollution target if all markets (including those not modelled) are assumed to be competitive, ${ }^{7}$ and are therefore superior in welfare terms, we use other measures of performance to compare these policies. ${ }^{8}$

Comparing tax and DRS policies that attain the same pollution target reveals that the rates of growth in price and output are equivalent, but the length of the productive life of capital is longer under DRS, as the relative cost of pollution imposed on aging capital is lower; as a result, the absolute level of output is generally higher under DRS than under taxes (and prices are lower). This confirms the result in the static model in Holland (2012), which shows that intensity standards imply an implicit output subsidy (see also the analysis of tradable performance standards in Fisher [2001]). However, the results obtained below also show that the pollution goal will be achieved using cleaner technologies under DRS, a result that is at odds with the previous literature, which has typically argued that performance standards (such as DRS) offer reduced incentives for the adoption of cleaner technologies (Zerbe 1970; Downing and White 1986; Milliman and Prince 1989; Jaffe and Stav-

5. Comparison of optimal policies would be complicated by the fact that the optimal level of pollution would be different under taxes than under DRS.

6. This analysis applies more to traditional emissions such as particular matter or sulphur dioxide; future work may apply it to stock pollutions.

7. Efficient in the sense that taxes maximize discounted economic surplus subject to the pollution constraint. As stated above, this result was already discussed in Johansen (1965). The proof for the model with vintages is available from the authors upon request.

8. Holland et al. (2009) provide further results showing that standards, in particular low carbon fuel standards, have costs in terms of efficiency. However, the analysis in Holland (2012) shows that intensity standards can be superior to taxes in welfare terms if there is leakage. 
ins 1995; Jung et al. 1996). As discussed in the concluding section, the different results obtained can explain the political economy of the prevalence of DRS in regulations worldwide (despite the fact that taxes are superior in welfare terms).

\section{TAXES ON POLLUTION}

\subsection{Firm Regulated by Taxes}

The analysis is performed using a micro-model based on firm behavior in which scrapping time is modeled explicitly. Assume that the ex ante production function that determines the technology of new production capacity at any given time follows a linear homogeneous Cobb-Douglas production function ${ }^{9}$ and that ex post production follows Leontief functions according to the putty-clay approach (Johansen 1959; Salter 1966). The state of technology at any given time is reflected by the multiplicative factor in the Cobb-Douglas function. Thus, technical changes are neutral and result in an isoelastic shift of the production function. To enable comparison of investments in different periods, capital in the ex ante production function is measured by the initial investment at constant prices, which requires the use of some price index of capital goods. More precisely, suppose production at time $t$ follows constant returns technology with unit isoquant

$$
1=e^{\eta t} A k(t)^{\alpha_{1}} l(t)^{\alpha_{2}} \gamma(t)^{\alpha_{3}},
$$

where $k(t)$ is the capital-output ratio, $l(t)$ is the labor-output ratio, $\gamma(t)$ is the polluting input to output ratio, with $\eta>0, A>0,0 \leq \alpha_{i} \leq 1$, for $i=1,2,3$, and $\alpha_{1}+\alpha_{2}+$ $\alpha_{3}=1$ (table 1 shows the notation used). To simplify the analysis, let capital be used as a numeraire so that the capital price index is constant; thus, without loss of generality, the price of capital input is identically 1 .

To bring the dynamic problem into tractable proportions that can be meaningfully discussed, factors exogenous to the firm are assumed to follow exponential growth paths in our partial equilibrium model (i.e., they are assumed to follow a balanced growth path of a more general model). For example, the wage rate relative to the price of capital is assumed to grow exponentially at a rate not exceeding the interest rate, ${ }^{10}$ and the multiplicative factors reflecting demand growth and the state of technology also grow exponentially. Finally, prices are exogenous to the firm and grow exponentially. The interest rate, however, is constant. That is, assume that

9. Without regulations or taxes on pollution, firms would produce infinite quantities of pollution; thus, feasible pollution-output ratios are assumed to be bounded from above.

10. This assumption, which postulates that wages grow exponentially and more rapidly than other prices, follows Salter's (1966) arguments and leads to the tendency toward capital-intensive technologies even with neutral technical change. This implies that obsolescence and not depreciation is the main driver to bring capital goods out of production. 
Table 1. Notation

\begin{tabular}{llll}
\hline$k$ & Capital-output ratio & $\alpha_{1}$ & Capital output elasticity \\
$l$ & Labor-output ratio & $\alpha_{2}$ & Labor output elasticity \\
$\gamma$ & Pollution-output ratio & $\alpha_{3}$ & Pollution output elasticity \\
$A$ & Total factor productivity scale coefficient & $r$ & Discount rate \\
$B$ & Scale coefficient of demand & $\eta$ & Rate of technical change \\
$w$ & Wage & $\psi$ & Growth rate for $w$ \\
$P$ & Output price & $\lambda d$ & Growth rate for $P$ \\
$v$ & Polluting input tax & $\phi$ & Growth rate for $v$ \\
$s$ & Rate of decline of pollution-ratio in DRS & $t$ & Time \\
$\bar{t}$ & Productive life of capital & $\tau$ & Time \\
$c$ & Rate of output capacity & $\delta$ & Demand growth rate \\
$X$ & Quantity demanded/produced by the industry & $\mu$ & Elasticity of demand \\
$Z$ & Total pollution & $z$ & Cohort pollution \\
$L$ & labor & $K$ & Capital \\
$Q$ & production & & \\
\hline
\end{tabular}

Note. $-v$ and $s$ in subscripts indicate values along a BGP for taxes and DRS, respectively; 0 in subscript indicates values along a BGP that reach a constant pollution level $\bar{Z}$.

$$
\begin{aligned}
& w(\tau)=w(t) e^{\psi(\tau-t)}, \\
& P(\tau)=P(t) e^{\lambda(\tau-t)},
\end{aligned}
$$

where $\psi$ is the rate of wage $(w(t))$ growth, and $\lambda$ is the rate of output price $(P(t))$ growth.

Pollution is considered as an additional input of the Cobb-Douglas function, as in Stokey (1998). The parameter $\gamma$ is a measure of the "dirtiness" of the machines used. An alternative rationalization for considering pollution as an input without a price is to view pollution as the quantity of environmental quality used in production. Both interpretations are reasonable representations for air quality, animal waste, and other cases where there is a by-product of pollution with no price or with an irrelevantly low price (it also provides an approximation for firms or industries where capital and labor are the main inputs).

However, frequently pollution is tied together with an input with a price, the prime example being energy (e.g., oil). The model could be modified to allow for this case, ${ }^{11}$ but we focus on the case where the price of the input is zero as the exposition

11. To modify the model to allow a price for the polluting input the most straightforward strategy is to interpret $\gamma$ as the energy ratio (assuming to simplify that 1 unit of energy implies 1 unit of pollution). The price to capital ratio of the pollution input for the firm at any given 
is clearer. Considering the growth in basic energy prices complicates the comparison between DRS and taxes. The reason is that the comparison is not anymore between a situation where pollution is priced (taxes) and one where it is not (DRS), but between a situation where pollution is fully priced and one where it is only partially priced (see also the discussion in Fullerton and Heutel [2010]). ${ }^{12}$ Thus, assume:

$$
v(\tau)=v(t) e^{\phi(\tau-t)},
$$

where $\phi$ is the rate of growth of the tax of the polluting input.

The assumption of constant returns to scale implies that the technologies are chosen to maximize the discounted profit per unit of new output capacity introduced. As labor costs are assumed to grow faster than other prices, as already noted, capacity introduced at time $t$ has a finite production life, denoted by $\bar{t}(t)$. Assuming that new capacity is introduced at every point in time and immediately put into production, firms utilize all the capacity introduced at time $t$ during the period $[t, t+\bar{t}(t)]$ and cease using it thereafter. ${ }^{13}$ This decision is based on marginal cost: at some time $\bar{t}$ after investment, marginal cost exceeds the price, and production from that vintage of capital ceases. However, the problem remains complex, as investors must decide not only whether to invest in the industry but also what type of machines to invest in. In particular, they need to decide the economic life and the capital, labor, and pollution intensity of their chosen machines. As the following analysis shows, the answer depends on the expected prices of labor and pollution over the lifetime of the machines (their initial price levels and their expected rate of change over time), relative to the price of the machines.

moment in time is then given by $v(\tau)=u_{1}(\tau)+u_{2}(\tau)$, where $u_{1}$ is the basic price of the polluting input and $u_{2}$ is the tax determined by the government (both as price-to-capital ratios). Then, assume that the price ratio of the polluting input, $v(\tau)$, grows at a constant rate, which is indirectly determined by the government when setting the tax-to-capital ratio on the pollution input (taking into account the autonomous growth that would result from market forces). The results presented in the main text essentially hold with this alternative model, as the relevant part for the firm is the total cost of the polluting input (but the growth of the tax has to be changed by the growth of the total cost of energy, basic price plus tax).

12. Fullerton and Heutel (2010) discuss a static general equilibrium model focused on the impact of mandates and taxes on wages and capital return (as in our model, the input "pollution" has a price equal to the tax, or no price when dealing with standards). Our paper differs in that it is a partial equilibrium model, and therefore input prices are exogenous, although it is dynamic and focuses on vintages.

13. This assumption and the focus on the equilibrium path without considering the impact of initial conditions and their role in producing echoes simplifies the analysis considerably. See Hritonenko and Yatsenko (2008) for an analysis that shows that, unless the initial conditions are "perfect," they will have a permanent impact and produce repeated echoes. 
Following the arguments above, using (2), (3), and (4), the optimal technology for time $t$ is determined by solving

$$
\max _{\bar{t}, k, l, \gamma} \int_{0}^{\bar{t}(t)}\left\{P(t) e^{-(r-\lambda) \tau}-w(t) l(t) e^{-(r-\psi) \tau}-\gamma(t) v(t) e^{-(r-\phi) \tau}\right\} d \tau-k(t),
$$

subject to (1). Computing the integral, the objective becomes

$$
\max _{\bar{t}, k, l, \gamma} \pi=\max _{\bar{t}, k, l, \gamma}\{\hat{P}(t, \bar{t})-[\hat{w}(t, \bar{t}) l(t)+\hat{v}(t, \bar{t}) \gamma(t)+k(t)]\},
$$

where

$$
\hat{P}(t, \bar{t})=\frac{P(t)}{f_{1}(\lambda, \bar{t})} ; \hat{w}(t, \bar{t})=\frac{w(t)}{f_{1}(\psi, \bar{t})} ; \hat{v}(t, \bar{t})=\frac{v(t)}{f_{1}(\phi, \bar{t})},
$$

with $f_{1}(a, \bar{t})=(r-a)\left[1-e^{-(r-a) t}\right]^{-1}$ for $a=\lambda, \psi, \phi{ }^{14}$ Note that $\hat{P}(t, \bar{t})$ is the discounted stream of revenues from a unit of output, $\hat{w}(t, \bar{t})$ are the lifetime wage costs and $\hat{v}(t, \bar{t})$ are the lifetime costs of a unit of emissions.

One can directly solve this optimization problem as it stands, ${ }^{15}$ but as it provides more intuition the analysis is done using the dual cost curve. Due to the putty-clay assumption, for each vintage of capital, the amount of labor, capital, and pollution emissions that is used is constant over the economic life of the capital, so the choice just depends upon the current value of each factor's cost over that horizon. For a given $\bar{t}$, the lifetime costs of using a particular vintage of capital are

$$
\Phi(t, \bar{t})=\min _{k, l, \gamma}[\hat{w}(t, \bar{t}) l(t)+\hat{v}(t, \bar{t}) \gamma(t)+k(t)]
$$

Following the standard procedure to find the dual cost function, that is, partially differentiating the production function (1), to find the marginal products, and equating it to the inverse of the input price ratios, using (7), one obtains

$$
\gamma(t)=l(t) \frac{\alpha_{3} \hat{w}(t, \bar{t})}{\alpha_{2} \hat{v}(t, \bar{t})} .
$$

This equation defines the points of least cost combination along the expansion path for $\gamma(t)$ and $l(t)$. Proceeding in the same manner for $k(t)$ and $l(t)$, one obtains the least cost combination along the expansion path for these inputs:

14. $f_{1}(a, \bar{t})$ is the principal and interest payment rate associated with amortization over a life of $\bar{t}$ at interest rate $(r-a)$.

15. This alternative proof is available from the authors upon request. 


$$
k(t)=l(t) \frac{\alpha_{1}}{\alpha_{2}} \hat{w}(t, \bar{t}) .
$$

Now, substituting (9) and (10) into (8) one has that, for the combination defining the minimum cost:

$$
\Phi(t, \bar{t})=l(t) \hat{w}(t, \bar{t})+\frac{\alpha_{3}}{\alpha_{2}} l(t) \hat{w}(t, \bar{t})+\frac{\alpha_{1}}{\alpha_{2}} l(t) \hat{w}(t, \bar{t}),
$$

or

$$
l(t) \hat{w}(t, \bar{t})=\alpha_{2} \Phi(t, \bar{t})
$$

Following the same steps, but writing the equivalents to (9) and (10) in terms of $\gamma(t)$ and $k(t)$, respectively, one obtains

$$
\begin{gathered}
\gamma(t) \hat{v}(t, \bar{t})=\alpha_{3} \Phi(t, \bar{t}), \\
k(t)=\alpha_{1} \Phi(t, \bar{t}) .
\end{gathered}
$$

Substituting (11) to (13) into (1) yields:

$$
\Phi(t, \bar{t})=\frac{\hat{w}(t, \bar{t})^{\alpha_{2}} \hat{v}(t, \bar{t})^{\alpha_{3}}}{A e^{\eta t} \prod_{i=1,2,3} \alpha_{i}^{\alpha_{i}}} .
$$

Using this information and the fact that, due to the zero profit assumption (see below), the economic lifetime of a vintage ends when

$$
P(t+\bar{t})=w(t+\bar{t}) l(t)+v(t+\bar{t}) \gamma(t)
$$

the following lemma is obtained:

Lemma 1: The optimal technology of machines introduced at time $t$ with pollution taxes follows

$$
\begin{aligned}
& k(t)=\frac{e^{-\eta t}}{A}\left[\frac{\alpha_{1}}{\alpha_{2}} \hat{w}(t, \bar{t})\right]^{\alpha_{2}}\left[\frac{\alpha_{1}}{\alpha_{3}} \hat{v}(t, \bar{t})\right]^{\alpha_{3}}, \\
& l(t)=\frac{e^{-\eta t}}{A}\left[\frac{\alpha_{2}}{\alpha_{1}} \hat{w}(t, \bar{t})\right]^{\alpha_{1}}\left[\frac{\alpha_{2}}{\alpha_{3}} \frac{\hat{v}(t, \bar{t})}{\hat{w}(t, \bar{t})}\right]^{\alpha_{3}}, \\
& \gamma(t)=\frac{e^{-\eta t}}{A}\left[\frac{\alpha_{3}}{\alpha_{1}} \frac{1}{\hat{v}(t, \bar{t})}\right]^{\alpha_{1}}\left[\frac{\alpha_{3}}{\alpha_{2}} \frac{\hat{v}(t, \bar{t})}{\hat{v}(t, \bar{t})}\right]^{\alpha_{2}},
\end{aligned}
$$




$$
P(t) e^{\lambda \bar{t}(t)}=w(t) e^{\psi \bar{t}(t)} l(t)+v(t) e^{\phi \bar{t}(t)} \gamma(t) .
$$

Proof: Substitute (14), respectively, into (13), (11), and (12) to obtain (16) to (18). Substitute (2) to (4) into (15), using (7), to get (19). QED

\subsection{Industry Regulated by Taxes}

As already stated, the equilibrium price at each point in time is determined such that profit is zero. ${ }^{16}$ This implies that the supply function in each moment in time is such that the price equals the average discounted costs associated with the newest technology (the technology used in this moment in time). Thus:

$$
P(t)=f_{1}(\lambda, \bar{t})[\hat{w}(t, \bar{t}) l(t)+\hat{v}(t, \bar{t}) \gamma(t)+k(t)] .
$$

Using the properties that

$$
\hat{w}(t, \bar{t})=\frac{\alpha_{2}}{\alpha_{1}} \frac{k(t)}{l(t)} \text { and } \hat{v}(t, \bar{t})=\frac{\alpha_{3}}{\alpha_{1}} \frac{k(t)}{\gamma(t)}
$$

obtains

$$
P(t)=f_{1}(\lambda, \bar{t}) \frac{k}{\alpha_{1}} .
$$

Furthermore, introducing the definition of $k(t)$ from (16) obtains

$$
P(t)=f_{1}(\lambda, \bar{t}) \frac{e^{-\eta t}}{A \alpha_{1}}\left[\frac{\alpha_{1}}{\alpha_{2}} \hat{w}(t, \bar{t})\right]^{\alpha_{2}}\left[\frac{\alpha_{1}}{\alpha_{3}} \hat{v}(t, \bar{t})\right]^{\alpha_{3}} .
$$

Given the assumption introduced above that new capacity is added at every point in time, the equilibrium price for each period satisfies $\hat{P}(t, \bar{t})=\Phi(t, \bar{t})$. Substituting this equation and (2), (3), (4), (7), and (11) to (13) into (15), and multiplying both parts by $e^{-r \bar{t}}$, obtains that the machines are retired when

16. Profit maximization implies that new investments are only made when $P(t) \geq A D C(t)$, where $A D C$ stands for average discounted costs (the right-hand side of eq. [20]). Thus, the supply function is rising for $P(t)<A D C(t)$, where only (part) of the existing capital is used and infinitely elastic for $P(t)=A D C(t)$, as it is assumed that it is possible to introduce as much new capital as wanted as soon as it becomes profitable to do so. Thus, the downwardsloping demand function defined in (20) intersects the supply function either in the rising portion of this function, in which case no new investment is made at time $t$, or in the elastic portion. Hence, given the assumption introduced above that new capacity is added continuously, demand intersects supply in the elastic portion of the supply function and the equilibrium price is given by (20). 


$$
f_{2}(\lambda, \bar{t})-\alpha_{2} f_{2}(\psi, \bar{t})-\alpha_{3} f_{2}(\phi, \bar{t})=0,
$$

where $f_{2}(a, \bar{t})=f_{1}(a, \bar{t}) e^{-(r-a) t}$ for $a=\lambda, \psi, \phi{ }^{17}$

Before continuing, let us state the following lemma, which is useful to analyze the long-term dynamics of the industry:

Lemma 2: The industry controlled by pollution taxes follows a balanced growth path (BGP) if the growth in output price is as defined in (25). ${ }^{18}$ Along this BGP the length of the productive life of capital is equal for all vintages, $\dot{\bar{t}}(t)=0$, and the rates of change of the capital, labor, and pollution input ratios are as follows:

$$
\begin{gathered}
\frac{\dot{P}(t)}{P(t)}=\frac{\dot{k}(t)}{k(t)}=\psi \alpha_{2}+\left(1-\alpha_{1}-\alpha_{2}\right) \phi-\eta=\lambda_{v}, \\
\frac{\dot{l}(t)}{l(t)}=\lambda_{v}-\psi, \frac{\dot{\gamma}(t)}{\gamma(t)}=\lambda_{v}-\phi, \\
\frac{k(t) / l(t)}{k(t) / l(t)}=\psi, \frac{k(t) / \gamma(t)}{k(t) / \gamma(t)}=\phi,
\end{gathered}
$$

where $v$ in subscripts indicates values along a BGP for taxes.

Proof: From (24) the optimal $\bar{t}$ is a function of variables that are independent of time. Equations (25) and (26) are verified by differentiating (16), (17), (18), and (22) with respect to time. Introducing (25) and (26) into $(k / l) /(k / l)=\dot{k} / k-\dot{l} / l$ and $(k / \gamma) /(k / l)=\dot{k} / k-\dot{\gamma} / \gamma$ obtains (27). QED

That is, lemma 2 shows the standard result that scrapping time is constant in equilibrium (Bliss 1968; Hjalmarsson 1974). Equation (27) indicates that along a BGP, more modern vintages have decreasing pollution ratios when the pollution input tax growth rate (relative to the capital price index) is positive. Using (26), one can deduce that, to be certain that more modern vintages will have decreasing pollution-output ratios, the tax growth rate must be higher than the output price growth rate. Additionally, equation (26) verifies that more modern vintages have increasing labor-pollution ratios if the pollution tax grows faster than wages (in

17. $f_{2}(a, \bar{t})$ is $f_{1}(a, \bar{t})$ discounted over the lifetime of the machine at the "net" discount rate $(r-a)$.

18. An economy (industry in this case) is in a state of balanced growth if all variables grow through time at constant exponential rates. 
what follows, we assume that $\lambda_{v}<\psi$ and $\left.\lambda_{v}<\phi\right) .{ }^{19}$ The lemma also shows that, as long as $\psi \alpha_{2}+\left(1-\alpha_{1}-\alpha_{2}\right) \phi-\eta>0$ (see eq. [25]), the assumption that prices grow exponentially is compatible with a BGP. ${ }^{20}$

The following proposition details the impact of different variables on the length of operation of the machines:

Proposition 1: For an industry following a BGP, the length of the period of operation of capital goods is decreasing in the rates of growth of the tax on the polluting input $(\phi)$, the labor wage $(\psi)$, and the neutral rate of technical change $(\eta)$.

Proof: See the appendix, sec. 1 .

Lemma 2 and proposition 1 examine the behavior of prices and productive capacity in an industry regulated by taxes. The effects on the industry, however, also depend critically on actual production, which is endogenous at the industry level. Nevertheless, demand is exogenous to the model and is given by

$$
X(t)=B e^{\delta t} P(t)^{-\mu}
$$

where $X(t)$ is quantity demanded per unit of time at time $t, \delta$ is the exogenous rate of growth of demand, $B$ is a scale coefficient of demand, and $\mu$ is the elasticity of demand. Introducing the price function (23) into (28), the equilibrium output rate function is given by

$$
X(t)=A^{\mu} B e^{(\delta-\mu \eta) t} f_{1}(\lambda, \bar{t})^{-\mu}\left[\frac{\alpha_{1}}{\alpha_{2}} \hat{w}(t, \bar{t})\right]^{-\mu \alpha_{2}}\left[\frac{\alpha_{1}}{\alpha_{3}} \hat{v}(t, \bar{t})\right]^{-\mu \alpha_{3}}
$$

19. Assuming that the output price growth rate is lower than the rate of growth of wages $(\lambda<\psi)$, the introduction of the expression for $\lambda$ from (26) into the last inequality yields a constraint on the feasible values of the policy variable $\phi$. This constraint is

$$
\phi<\psi\left(1+\frac{\alpha_{1}}{\left(1-\alpha_{1}-\alpha_{2}\right)}\right)+\frac{\eta}{\left(1-\alpha_{1}-\alpha_{2}\right)} .
$$

As in most cases the capital share is higher than the pollution share, and the pollution share is very small, the upper bound on the rate of growth of the pollution tax is significantly higher than the wage growth rate. Policies considered in the rest of this work are assumed to comply with this constraint.

20. Following Johansen (1972) we assume that the price grows exponentially and by solving the model show that it actually grows exponentially (note also that introducing the price equation into [28] obtains that output also grows exponentially [see eq. (30)], completing the characterization of the BGP). This exponential growth is imposed by the fixed input elasticities of the Cobb-Douglas function and the constant rate of growth of the input prices. 
Differentiating (29) and taking into account $\dot{\bar{t}}(t)=0$, it is trivial to show that, for an industry regulated by a tax following a BGP, the dynamic path of output grows at a constant exponential rate, say $\rho_{v}$, which is equal to the rate of growth of demand minus the rate of growth in output price multiplied by the elasticity of demand. That is, in equilibrium,

$$
\frac{\dot{X}(t)}{X(t)}=\left(\delta-\mu \lambda_{v}\right)=\delta-\mu\left[\psi \alpha_{2}+\left(1-\alpha_{1}-\alpha_{2}\right) \phi-\eta\right]=\rho_{v} .
$$

Remark 1: By (30) the dynamic path of output of an industry is described by $X(t)=X(0) e^{\rho_{t} t}$. The rate of output growth is affected negatively by the rates of growth of wages and the polluting input tax. The wage and tax levels at time $t=0$ affect only the level of output production but not the rate of output growth.

By lemma 2, a BGP price path for the industry results in a constant length of operation period, $\bar{t}$, for all vintages (i.e., output at time $t$ is produced only by capital goods with age no greater than $\bar{t}$ and active vintages at $t$ are defined by the segment $[t-\bar{t}, t])$. Thus,

$$
X(t)=\int_{t-\bar{t}}^{t} c(\tau) d \tau
$$

where $c(\tau)$ is the rate of output capacity introduced at time $\tau$. Similarly, the rates of labor use and pollution generation at time $t$ by an industry along a BGP are:

$$
\begin{aligned}
& L(t)=\int_{t-\bar{t}}^{t} l(\tau) c(\tau) d \tau, \\
& Z(t)=\int_{t-\bar{t}}^{t} \gamma(\tau) c(\tau) d \tau .
\end{aligned}
$$

The function $c(\tau)$ is computed by differentiating $X(t)$ with respect to time:

$$
c(t)=\dot{X}(t)+c(t-\bar{t}) .
$$

By differentiation of $X(\tau)$ with respect to time at $\tau=t-n \bar{t}$, one finds

$$
c(t-n \bar{t})=\dot{X}(t-n \bar{t})+c[t-(n+1) \bar{t}] \text { for } n=0,1, \ldots, \infty .
$$

By applying (35) recursively, $c(t)$ can be represented as

$$
c(t)=\sum_{j=0}^{\infty} \dot{X}\left(t-\bar{t}_{v} j\right)=\rho_{v} X(0) e^{-\rho_{v} \bar{t}_{j} j}=\frac{\rho_{v} X(0) e^{\rho_{t} \bar{t}_{v}}}{1-e^{-\rho_{v} \bar{t}_{v}}} .
$$


Inserting $\gamma(t)=\gamma(0) e^{(\gamma-\phi) t}$ and (36) into (33) also yields

$$
Z(t)=\int_{t-\bar{t}}^{t} \frac{\rho X(0) \gamma(0) e^{\left(\rho_{v}+\lambda_{v}-\phi\right) \tau}}{1-e^{-\rho_{v} \bar{t}_{v}}} d \tau=\frac{\rho_{v} X(0) \gamma(0) e^{\left(\rho_{v}+\lambda_{v}-\phi\right) \bar{t}_{v}}\left[1-e^{-\left(\rho_{v}+\lambda_{v}-\phi\right) \bar{t}_{v}}\right]}{\left(\rho_{v}+\lambda_{v}-\phi\right)\left(1-e^{-\rho_{v} \bar{t}_{v}}\right)} .
$$

This proves:

Proposition 2: For an industry following a BGP, the rate of growth of new output capacity is equal to the rate of growth in production, that is,

$$
\frac{\dot{c}(t)}{c(t)}=\rho_{v}
$$

and the rate of growth in pollution is equal to the rate of growth in output plus the rate of growth of the pollution input ratio, that is,

$$
\frac{\dot{Z}(t)}{Z(t)}=\rho_{v}+\frac{\dot{\gamma}(t)}{\gamma(t)}=\rho_{v}+\lambda_{v}-\phi
$$

To facilitate the comparison with DRS below, consider the special case of constant total pollution emissions $\bar{Z}$, which is consistent with balanced growth. Denoting values along a BGP that reach a constant pollution level $\bar{Z}$ by a 0 in the subscript, we can write the following remark.

Remark 2: A pollution tax that implies an exponentially growing pollution input tax can limit the rate of growth of pollution over time or sustain a certain pollution level for an industry following a BGP. The rate of growth of the polluting input tax that ensures a constant pollution level, that is, $\bar{Z}(t)=\bar{Z}$ for all $t$, is derived from (39) by setting $\dot{Z}(t)=0$ and using (25) and (30):

$$
\phi_{0}=\frac{\left(\alpha_{2} \psi-\eta\right)(1-\mu)+\delta}{\mu\left(1-\alpha_{1}-\alpha_{2}\right)+\left(\alpha_{1}+\alpha_{2}\right)}
$$

From (40), one finds that the pollution tax which ensures a constant pollution rate may decline with time, for example, with a low rate of demand growth, $\delta$, slow wages growth, $\psi$, low elasticity of demand $(\mu<1)$, and a high rate of technical change, $\eta$. In this case, even a decreasing pollution tax leads to a decline in the pollution/output ratio due to technical progress. Thus, if demand is inelastic, fewer inputs will be used to produce the equilibrium output.

By introducing $\phi=\phi_{0}$ into (30), the rate of growth of output when the pollution level is constant can be determined as a function of $\delta, \mu, \psi, \eta, \alpha_{1}$, and $\alpha_{2}$. Also, using (26), the rate of growth in the pollution-output ratio corresponding to $\phi=\phi_{0}$ is $\dot{\gamma}(t) / \gamma(t)=-\rho_{v 0}$. 
A tax policy which ensures that an industry is following a BGP generates a constant level of pollution consists of two parameters. The first parameter is the rate of growth of the pollution tax indirectly given by equation (40), which ensures that the rate of pollution growth is zero. The second parameter $\left(v_{0}(0)\right)$, the tax at time zero which ensures that $Z(t)=Z(0)=\bar{Z} \forall t$, is given in the following lemma.

Lemma 3: An industry following a BGP generates a constant level of pollution $\bar{Z}$ if the pollution tax rate grows exponentially with rate $\phi_{0}$; and the initial polluting input tax at time 0 is a decreasing homogeneous function of the pollution goal of the form:

$$
v_{0}(0)=b_{1} \bar{Z}^{-b_{2}}
$$

where

$$
\begin{aligned}
& \left.\left.b_{1}=\left\{\frac{\bar{t}_{v 0} \rho_{v 0} A^{\mu-1} B f_{1}\left(\lambda_{v 0}, \bar{t}_{v 0}\right)^{-\mu}}{\left[1-e^{-\rho_{v 0} \bar{t}_{00}}\right]} \frac{f_{1}\left(\psi, \bar{t}_{v 0}\right) \alpha_{2}}{w(0)}\right]^{\alpha_{1}^{-\alpha_{1}(\mu-1)}}\right\}^{\alpha_{2}(\mu-1)}\right\}^{b_{2}} \alpha_{3} f_{1}\left(\phi_{v 0}, \bar{t}_{v 0}\right), \\
& b_{2}=\left[\alpha_{1}+\alpha_{2}+\alpha_{3} \mu\right]^{-1} .
\end{aligned}
$$

Proof: See the appendix, sec. 2.

For this special case, both total emissions $\bar{Z}$ and machine lifetime $\bar{t}$ are constant. Furthermore, any machine once made emits pollution at a fixed rate during its lifetime. It follows that total emissions from each "cohort" of machines (the collection of all machines of a given vintage) must be equal. Denoting emissions from that cohort as $z$ obtains $\bar{Z}=z \bar{t}$ (i.e., total emissions are equal to emissions per cohort times the mass of cohorts). Since both $z$ and $\bar{t}$ are constant, total emissions $\bar{Z}$ are also constant. However, note that $z$ is the product of total production from the given vintage and the pollution intensity of the machines of that vintage. Thus, low pollution intensity allows more production for a given cap on $z$, but, on the other hand, more of the other inputs (capital and labour) are required to achieve a given level of production.

\section{DYNAMIC RELATIVE STANDARDS}

As discussed in the introductory section, in many cases pollution is not controlled by taxation but by direct regulations (standards). This section analyzes a particular kind of standard: an upper bound on the pollution-output ratio of new machines. This standard may become more stringent with time; that is, the upper bound on the pollution-output ratio may be reduced for more modern technologies (justifying the name DRS). The particular assumption in this section is that the pollutionoutput ratio standard declines exponentially. ${ }^{21}$

21. Stokey (1998) provides a theoretical rationale for an exponentially decreasing standard from a social planner's point of view in the centralized economy. 


\subsection{Firm Regulated by DRS}

Let $\bar{\gamma}(t)$ denote the upper bound set by the regulator on the pollution-output ratio of machines of vintage $t$ and let this upper bound decrease with time at a constant rate following $\bar{\gamma}(t)=\bar{\gamma}(0) e^{-s t}$, with $s \geq 0$, where $\bar{\gamma}(0)$ is the upper bound on the pollution-output ratio of machines introduced at time zero and $s$ is the rate of decline of the pollution-output ratio. ${ }^{22}$ The optimization problem is now:

$$
\max _{\bar{t}, k, l, \gamma} \int_{0}^{\bar{t}(t)}\left\{P(t) e^{-(r-\lambda) \tau}-w(t) l(t) e^{-(r-\psi) \tau}\right\} d \tau-k(t),
$$

subject to (1) and $\gamma(t) \leq \bar{\gamma}(t)$. The analysis that follows assumes that the constraint is binding at all times (as the price of the pollution input is zero, it is unproblematic to assume that profit maximizers will operate with the highest feasible pollution output ratio). Introducing $\gamma(t)=\bar{\gamma}(t)$ into (1), the ex ante production function at time $t$ becomes

$$
Q(t)=e^{\eta t} A K(t)^{\alpha_{1}} L(t)^{\alpha_{2}}[\bar{\gamma}(t) Q(t)]^{\alpha_{3}} .
$$

This relationship can be rearranged as

$$
\begin{aligned}
Q(t) & =\left[A e^{\eta \bar{\gamma}} \bar{\gamma}(t)^{\alpha_{3}}\right]^{1 /\left(\alpha_{1}+\alpha_{2}\right)} K(t)^{\alpha_{1} /\left(\alpha_{1}+\alpha_{2}\right)} L(t)^{\alpha_{2} /\left(\alpha_{1}+\alpha_{2}\right)} \\
& =\left[A \bar{\gamma}_{0}^{\alpha_{3}}\right]^{1 /\left(\alpha_{1}+\alpha_{2}\right)} e^{\left\{\left[\eta-s \alpha_{3}\right] /\left(\alpha_{1}+\alpha_{2}\right)\right\} t} K(t)^{\alpha_{1} /\left(\alpha_{1}+\alpha_{2}\right)} L(t)^{\alpha_{2} /\left(\alpha_{1}+\alpha_{2}\right)} \\
& =\tilde{A} e^{\tilde{\eta} t} K(t)^{\tilde{\alpha}_{1}} L(t)^{\tilde{\alpha}_{2}} .
\end{aligned}
$$

Thus, the ex ante production function of an industry with a constrained pollutionoutput ratio $\bar{\gamma}(t)$ is treated by the entrepreneurs as a Cobb-Douglas production function of capital and labor, with coefficients $\tilde{\alpha}_{i}=\alpha_{i}\left(\alpha_{1}+\alpha_{2}\right)^{-1}, i=1,2$, scale parameter $\tilde{A}=\left[A \bar{\gamma}_{0}^{\alpha_{3}}\right]^{1 /\left(\alpha_{1}+\alpha_{2}\right)}$, and neutral rate of technical change $\tilde{\eta}=\left(\eta-s \alpha_{3}\right)\left(\alpha_{1}+\alpha_{2}\right)^{-1}$ (we call this the "relevant" production function under DRS). Since, under DRS, pollution is costless, the share coefficients of labor and capital for the relevant production function are larger than the actual share coefficients. Furthermore, the deviations of the relevant share coefficient from the actual ones are increased with the actual coefficient of pollution.

Proceeding as for taxes, the equivalents to (11) and (13) are now:

$$
l(t) \hat{w}(t, \bar{t})=\frac{\tilde{\alpha}_{2}}{\tilde{\alpha}_{1}+\tilde{\alpha}_{2}} \tilde{\Phi}(t, \bar{t}) \text { and } k(t)=\frac{\tilde{\alpha}_{1}}{\tilde{\alpha}_{1}+\tilde{\alpha}_{2}} \tilde{\Phi}(t, \bar{t}),
$$

22. While the pollution-output ratio bound is assumed to decline over time, for purposes of discussion, the analysis also holds if the bound increases, in which case $s<0$. 
with $\tilde{\Phi}(t, \bar{t})=\min _{k, l}[\hat{w}(t, \bar{t}) l(t)+k(t)]$. Substituting these expressions into (44) obtains

$$
\tilde{\Phi}(t, \bar{t})=\frac{\hat{w}(t, \bar{t})^{\tilde{\alpha}_{2}}}{\tilde{\alpha}_{1}^{\tilde{\alpha}_{1}} \tilde{\alpha}_{2}^{\tilde{\alpha}_{2}}\left(A e^{\eta t} \bar{\gamma}(t)^{\alpha_{3}}\right)^{1 /\left(\alpha_{1}+\alpha_{2}\right)}} .
$$

Using this information, and that the equivalent to (15) is now $P(t+\bar{t})=w(t+\bar{t}) l(t)$, the following lemma is found:

Lemma 4: The optimal technology of machines introduced at time $t$ under DRS follows

$$
\begin{gathered}
k(t)=\left[\frac{e^{-\left(\eta-s \alpha_{3}\right) t}}{A \bar{\gamma}(0)^{\alpha_{3}}}\right]^{1 /\left(\alpha_{1}+\alpha_{2}\right)}\left[\frac{\alpha_{1}}{\alpha_{2}} \hat{w}(t, \bar{t})\right]^{\alpha_{2} /\left(\alpha_{1}+\alpha_{2}\right)}, \\
l(t)=\left[\frac{e^{-\left(\eta-s \alpha_{3}\right) t}}{A \bar{\gamma}(0)^{\alpha_{3}}}\right]^{1 /\left(\alpha_{1}+\alpha_{2}\right)}\left[\frac{\alpha_{2}}{\alpha_{1}} \hat{\hat{w}(t, \bar{t})}\right]^{\alpha_{1} /\left(\alpha_{1}+\alpha_{2}\right)}, \\
\gamma(t)=\bar{\gamma}(0) e^{-s t}, \\
P(t) e^{\lambda \bar{t}(t)}=w(t) e^{\bar{\psi}(t)} l(t) .
\end{gathered}
$$

\subsection{Industry Regulated by DRS}

The equivalent to (24) is now

$$
\left(\alpha_{1}+\alpha_{2}\right) f_{2}(\lambda, \bar{t})-\alpha_{2} f_{2}(\psi, \bar{t})=0 .
$$

From this equation it becomes evident that, for an industry regulated by DRS following a BGP, the productive life of capital is equal in equilibrium for all vintages.

Equation (22) and those shown in lemma 2 become now ( $s$ in subscripts indicates values along a $\mathrm{BGP}$ for $\mathrm{DRS})$ :

$$
\begin{gathered}
P(t)=f_{1}(\lambda, \bar{t}) k(t)\left(\alpha_{1}+\alpha_{2}\right) \alpha_{1}^{-1}, \\
\frac{\dot{P}(t)}{P(t)}=\frac{\dot{k}(t)}{k(t)}=\psi \frac{\alpha_{2}}{\alpha_{1}+\alpha_{2}}-\frac{\eta-s\left(1-\alpha_{1}-\alpha_{2}\right)}{\alpha_{1}+\alpha_{2}}=\lambda_{s}, \\
\frac{\dot{l}(t)}{l(t)}=\lambda_{s}-\psi, \frac{\dot{\gamma}(t)}{\gamma(t)}=-s .
\end{gathered}
$$

The equivalent to (30) shows now that, for an industry regulated by DRS, the rate of output growth is equal to the rate of growth of demand minus the rate of growth in output price multiplied by the elasticity of demand: 


$$
\frac{\dot{X}(t)}{X(t)}=\left(\delta-\mu \bar{\gamma}_{s}\right)=\delta-\mu \frac{\psi \alpha_{2}-\left[\eta-s\left(1-\alpha_{1}-\alpha_{2}\right)\right]}{\alpha_{1}+\alpha_{2}}=\rho_{s} .
$$

Proceeding as for equation (36) one finds:

$$
c(t)=\frac{\rho_{s} X(0) e^{\rho_{s} \bar{t}_{s}}}{1-e^{-\rho_{s} \bar{t}_{s}}} .
$$

Also note that using $\gamma(t)=\bar{\gamma}(0) e^{-s t}$ and (54) in $Z(t)=\int_{t-\bar{t}_{s}}^{t} \gamma(\tau) c(\tau) d \tau$ obtains

$$
Z(t)=\frac{\rho_{\bar{\gamma}} \bar{\gamma}(0) X(0) e^{\left(\rho_{s}-s\right) \bar{t}_{t}}\left[1-e^{-\left(\rho_{s}-s\right) \bar{t}_{s}}\right]}{\left(\rho_{s}-s\right)\left(1-e^{-\rho_{s} \bar{t}_{s}}\right)} .
$$

This proves:

Proposition 3: For an industry regulated by DRS following a BGP, the rate of growth of new output capacity is equal to the rate of growth of output, that is,

$$
\frac{\dot{c}(t)}{c(t)}=\rho_{s}
$$

and the rate of growth of pollution is equal to the rate of growth of output minus the rate of growth of the pollution-output ratio of new technologies, that is,

$$
\frac{\dot{Z}(t)}{Z(t)}=\rho_{s}-s
$$

Remark 3: Condition (57) indicates that, for an industry regulated by a DRS which generates a constant level of pollution following a BGP, the rate of decline in the pollutionoutput ratio of new technologies is equal to the rate of growth in output, that is,

$$
\rho_{s 0}=s_{0},
$$

where $s_{0}$ is the rate of decline in the pollution-output ratio of new technologies that ensures $Z(t)=\bar{Z}$.

To develop further results in the following section comparing taxes and DRS, the following lemma is also useful (the proof is analogous to that of lemma 3, writing $X_{s 0}(0)$ as a function of $\bar{\gamma}_{s 0}(0)$, and is omitted).

Lemma 5: An industry following a BGP generates a constant level of pollution $\bar{Z}$ if it is regulated by a standard restricting the pollution-output ratio of new machines which is decreasing exponentially with the rate $s_{0}$ given by 


$$
s_{0}=\frac{\delta\left(\alpha_{1}+\alpha_{2}\right)-\mu\left(\psi \alpha_{2}-\eta\right)}{\left(\alpha_{1}+\alpha_{2}\right)+\mu\left(1-\alpha_{1}-\alpha_{2}\right)}
$$

and the upper bound on the pollution-output ratio of machines of vintage zero is given by $\bar{\gamma}_{s 0}(0)=d \bar{Z}^{\left(\alpha_{1}+\alpha_{2}\right) b_{2}}$, where

$$
d=\frac{1}{A^{\mu b_{2}}}\left[\frac{\rho_{s 0} \bar{t}_{s 0} B}{\left(1-e^{\left.-\rho_{s} \bar{t}_{0}\right)}\right.}\left(\frac{\alpha_{1}+\alpha_{2}}{\alpha_{1}} f_{1}\left(\lambda_{s 0}, \bar{t}\right)\right)^{-\mu}\right]^{-\left(\alpha_{1}+\alpha_{2}\right) b_{2}}\left[\frac{\alpha_{1}}{\alpha_{2}} \hat{w}\left(0, \bar{t}_{s 0}\right)\right]^{-\mu \alpha_{2} b_{2}} .
$$

\section{TAXES VERSUS DYNAMIC RELATIVE STANDARDS}

It is possible to attain a constant level of pollution with either taxes or DRS, as lemmas 3 and 5 have shown. Thus, it is interesting to compare the dynamic behavior of other variables when both taxes and DRS attain the same constant level of pollution in a BGP. The following remark collects some of the results already obtained, and the results thereafter compare the effects of these policies.

Remark 4: It follows from (25) and (51) that the contribution of the rate of wage growth to the rates of price increase and capital intensification is larger under DRS than under taxes. Under DRS, this contribution is increasing with the share coefficient of pollution.

That is, as in Averch and Johnson (1962), the regulated firm is more capital intensive. Furthermore, this capital intensification is stronger under DRS.

Subtracting (25) from (51), and using (26) and (52) yields:

$$
\lambda_{s}-\lambda_{v}=\left(1-\alpha_{1}-\alpha_{2}\right)\left(\lambda_{s}+s-\phi\right)=\frac{\left(1-\alpha_{1}-\alpha_{2}\right)}{\left(\alpha_{1}+\alpha_{2}\right)}\left(\frac{\dot{\gamma}_{v}(t)}{\gamma_{v}(t)}-\frac{\dot{\gamma}_{s}(t)}{\gamma_{s}(t)}\right) .
$$

Thus, $\lambda_{s}$ is larger, equal to, or smaller than $\lambda_{v}$ depending upon the reduction in the pollution-output ratio. To facilitate the comparison between the two instruments in a homogeneous setting, the following propositions focus on the situation where a constant pollution level is achieved under both policies, as this implies that $\left[\dot{\gamma}_{v 0}(t)\right] /\left[\gamma_{v 0}(t)\right]=\left[\dot{\gamma}_{s 0}(t)\right] /\left[\gamma_{s 0}(t)\right]$ and therefore $\lambda_{v 0}=\lambda_{s 0}=\lambda_{0}$. This allows us to write:

Proposition 4: For an industry following a BGP that generates a constant pollution level, the rates of growth of price and output and the rate of decline in the pollutionoutput ratio of new technologies are the same whether pollution is regulated by taxes or by DRS, that is,

$$
-\frac{\dot{\gamma}_{0}(t)}{\gamma_{0}(t)}=s_{0}=\rho_{s 0}=\frac{\delta\left(\alpha_{1}+\alpha_{2}\right)-\mu\left(\psi \alpha_{2}-\eta\right)}{\left(\alpha_{1}+\alpha_{2}\right)+\mu\left(1-\alpha_{1}-\alpha_{2}\right)}=\rho_{0} .
$$


Proof: The first equality of (60) follows from (52), the second from (58), the third from (59), and the fourth by substituting (40) into (30). The remaining assertions follow trivially. QED

Even though the rates of growth of prices, output, and pollution are equal under taxes and DRS, ${ }^{23}$ their levels are not necessarily identical when both policies are directed at attaining the same constant pollution level. One reason for the possible difference is that the length of life of capital is not necessarily identical under both policies as the following proposition shows.

Proposition 5: For an industry regulated to attain a constant pollution level along a BGP, length of the productive life of capital is equal under both policies if the output of the industry is constant, while it is longer under DRS than under taxes if the output of the industry is growing.

Proof: See the appendix, sec. 3.

Remark 5: One explanation of the shorter productive life of capital under taxes is that the burden of pollution taxation becomes heavier as a capital good ages, while under DRS a firm is not burdened by the pollution it generates.

A constant output of the industry restricted to a constant pollution level along a BGP implies the following relationship between parameters (from [25] and [30]):

$$
\delta\left(\alpha_{1}+\alpha_{2}\right)=\mu\left(\psi \alpha_{2}-\eta\right) .
$$

In this case-as pollution emissions per cohort, $z$, are held constant-the pollution intensity of production, $\gamma_{0}$, must be constant. A constant $\gamma_{0}$ implies that the pollution tax must rise at the growth rate of output price, and obviously that $\gamma_{0}$ must be constant for DRS. The consequence is that when $\rho_{0}=0$ the lifetime of machines is identical under both instruments (as eqs. [24] and [49] are identical for $\lambda_{0}=\phi_{0}$ ). The key difference is that output is higher under DRS (see proposition 6), because price is lower as firms in the industry do not have to pay the tax (see Fisher 2001; Holland 2012). Since output is higher this also implies that the pollution intensity of production must be lower. In other words, DRS impose lower costs on the industry compared to taxes, allowing the industry to grow larger, implying that pollution intensity must be lower.

23. Thus, the anti-inflation argument in favor of standards (Hochman and Zilberman 1978) only has merit on a one-time basis in the context of changing from taxes to standards; after adjustment, the rate of inflation is the same as under tax regulation. 
When industry output is rising (loosely, when demand is rising faster than costs), one knows that the pollution tax rises faster than the price of the final product as long as

$$
\delta\left(\alpha_{1}+\alpha_{2}\right)>\mu\left(\psi \alpha_{2}-\eta\right),
$$

which is the condition for rising output; see equation (61) above (to obtain [62] observe that $\phi>\lambda_{\mathrm{v}}$ implies $\left(\psi \alpha_{2}-\eta\right) /\left(\alpha_{1}+\alpha_{2}\right)<\lambda_{v}$, by [25], and substitute this result into [30]). When the pollution tax rises faster than the price of the final product, the tax weighs relatively heavily on old vintages compared to DRS (which by construction remains fixed over time for a given vintage) and this causes old vintages to be retired earlier under taxes, compared to DRS. Although the analysis is now more complex, in general the intuitive difference between the two instruments discussed in the previous paragraph continues to hold, that is, that output is higher in the DRS economy, because price is lower as firms in the industry do not have to pay the tax, which implies that pollution intensity of production must be lower. The following proposition provides conditions for this to hold.

Proposition 6: For an industry restricted to a constant pollution level along a BGP, DRS yield higher output than taxes, that is, $X_{s 0}(t)>X_{v 0}(t) \forall t$, if

$$
\begin{gathered}
\frac{\left(\left(\alpha_{1}+\alpha_{2}\right) f_{3}\left(r-\lambda_{0}\right)\right)^{\left(\alpha_{1}+\alpha_{2}\right) /\left(1-\alpha_{1}-\alpha_{2}\right)}}{f_{3}(r-\psi)^{\alpha_{2} /\left(1-\alpha_{1}-\alpha_{2}\right)}} f_{3}\left(\rho_{0}\right)<\frac{\bar{t}_{v 0}}{\bar{t}_{s 0}}, \\
\text { with } f_{3}(a)=\frac{1-e^{-a \bar{t}_{0}}}{1-e^{-a \bar{t}_{0}}} .
\end{gathered}
$$

This condition holds if $\rho_{0}=0$ or if

$$
\left(\alpha_{1}+\alpha_{2}\right)^{\left(\alpha_{1}+\alpha_{2}\right) /\left(1-\alpha_{1}\right)}<\frac{\bar{t}_{v 0}}{\bar{t}_{s 0}}
$$

Proof: See the appendix, sec. 4.

Proposition 6 shows that the output is higher under DRS than under taxes if (63) holds. However, it also gives two sufficient conditions. First, it holds if output is not growing in the industry $\left(\rho_{0}=0\right)$. But even if output grows, the second sufficient condition (64) holds for most plausible values, as long as the pollution output elasticity is sufficiently large. ${ }^{24}$ As already noted, the intuition for the result

24. For example, if $\alpha_{3}=1-\alpha_{1}-\alpha_{2}>0.2$, condition (64) holds for any distribution of $\alpha_{1}$ and $\alpha_{2}$ as long as the increase in the length of operation of capital is less than $20 \%$ (or $25 \%$ if we also have $\alpha_{1}>0.2$ ). If $\alpha_{3}>0.3$, condition (64) holds for any distribution of $\alpha_{1}$ and $\alpha_{2}$ as long as the reduction in length of operation of capital is less than $28 \%$ (or $42 \%$ if 
is that a sufficiently large pollution coefficient will lead to a sufficiently large tax so that output price under tax will be higher than under DRS (as pollution is not priced for the latter). The following set of simulations confirms this.

Example 1: To show that condition (63) generally holds we performed 5,000 Monte Carlo simulations for an industry regulated to attain a constant pollution level along a BGP, with $r \in(0.02,0.06),{ }^{25} \psi, \delta, \mu \in(0.01, r-0.005), \alpha_{1}, \alpha_{2} \in(0.1,0.45)$, and $\eta \in\left(0.01, \delta+\psi \alpha_{2}\right)$. In all cases, condition (63) was fulfilled and, as predicted by proposition $6, X_{s 0}(t)>X_{v 0}(t)$. As in all cases $\rho_{0}>0$, and as predicted by proposition 5 , in all cases $\bar{t}_{v 0}<\bar{t}_{50}$. The increase in scrapping time was larger than $20 \%$ in about $1 \%$ of the cases, larger than $10 \%$ in $6 \%$ of the simulations, larger than $5 \%$ in $17 \%$ of the cases, and larger than $1 \%$ in $67 \%$ of the simulations.

Thus, assume for what follows that (63) holds. As proposition 5 showed that $\bar{t}_{v 0}<\bar{t}_{s 0}$ when $\rho_{0}>0$, the product of output with the pollution-output coefficient of the newest machine at time zero has to be larger under taxes than under DRS;

$$
X_{v 0}(0) \gamma_{v 0}(0)>X_{s 0}(0) \gamma_{s 0}(0) \text { when } \rho_{0}>0
$$

Condition (65) excludes the possibility that DRS result in both higher output and pollution-output ratios. The discussion of proposition 6 has also shown that in general $X_{v 0}(0)<X_{s 0}(0)$ even when $\rho_{0}>0$. Hence, the pollution-output ratio under DRS has to be lower than under taxes for (65) to hold, that is, $\gamma_{s 0}(0)<\gamma_{\nu 0}(0)$, which implies $\gamma_{s 0}(t)<\gamma_{v 0}(t) \forall t$ as both evolve at the same constant rate as shown in proposition 4. That is, less-polluting machines are introduced under DRS (i.e., DRS induce less pollution-intensive production), but machines are utilized for a longer period of time in meeting the same aggregate pollution target. The following corollary highlights this result:

Corollary 1: For an industry restricted to a constant pollution level along a BGP and for which condition (63) holds, less-polluting machines are introduced under DRS than under taxes.

we also have $\left.\alpha_{1}>0.3\right)$. In addition, one has to take into account that condition (64) is much more demanding than condition (63), as it is obtained for the worst possible case (i.e., assuming that $f_{3}\left(\rho_{0}\right)$ and $f_{3}\left(r-\lambda_{0}\right)$ are at their largest possible values while $f_{3}(r-\psi)$ is at its smallest).

25. The parameters used in each simulation were taken randomly from the intervals shown, excluding sets of parameters that violated $0<\lambda_{v}<\psi, \phi$, the condition shown in $\mathrm{n} .19$, or for which there was no solution for $\bar{t} \leq 200$. Detailed simulation results, and the $\mathrm{R}$ code used, are available upon request. 


\section{CONCLUSION}

This paper analyzes the dynamic implications of exponentially increasing pollution taxes and exponentially decreasing pollution standards (dynamic relative standards) aimed at reaching a particular pollution goal. Comparison of both instruments has shown that, in general, the life of capital is longer, output is larger, and prices are lower with DRS. Thus, new capital goods are generally more polluting under taxes than under DRS.

This implies that, for different reasons, several players may prefer DRS over taxes (as argued by Buchanan and Tullock [1975], political economics of pollution control may lead to selection of policies that are not efficient or cost effective if powerful political groups prefer these policies). Consumers may focus on lower prices, without considering that higher taxes ultimately imply higher overall benefits, green lobbies probably celebrate the introduction of new cleaner technologies in the market, and trade unions and governments likely favor higher output and employment levels (especially if markets are not perfect and unemployment exists). Producers and other interests group may lose ${ }^{26}$ but the importance of the relative advantages of DRS (lower prices, higher output, and the introduction of cleaner technologies) may explain the popularity of this instrument, even though taxes are more efficient if all markets are assumed to be competitive, ${ }^{27}$ and DRS are therefore not superior in welfare terms.

The particular production function used implies constant returns to scale and constant output elasticities. With a more general formulation, allowing, for example, output elasticities to evolve over time, the constant scrapping time in equilibrium may not hold, rendering an analytic comparison between the outcomes under taxes and DRS intractable. Although a complete analysis of this issue would require an expanded model and probably resorting to simulations, the results that under DRS the productive life of capital is longer and the pollution goal is achieved using cleaner technologies would probably continue to hold, as the intuition for these results discussed above would still be valid. ${ }^{28}$

26. Unlike in Buchanan and Tullock's (1975) analysis, producers will not necessarily support DRS, as they generally imply more output and lower prices (although the rates of growth of output and prices are the same under both schemes). More precisely, producers will prefer DRS as long as the loss in producer surplus due to the reduction in price is compensated by the taxes avoided.

27. See n. 7.

28. Although new models would be needed to properly analyze these issues, even with endogenous technical change or stochastic shocks along the path the following intuition would probably hold: (i) life of capital is longer under DRS because the burden of pollution becomes heavier with taxes as capital ages (remark 5), and (ii) prices are lower under DRS because pollution is not fully priced, which implies higher output and ultimately cleaner technologies. 
The analysis of this paper may be expanded in several directions. One is to internalize R\&D expenditures and the probability of new discoveries (Montero [2002]) obtains, in a completely different framework, some results that are relatively similar to those presented here). Another would be to explicitly model a scrapping subsidy, perhaps combined with a scrapping cost (which would probably bring the results close to those obtained with the optimal tax). One could also consider analyzing a discrete and finite number of changes in the stringency of the standards (as this would bring the analysis closer to reality). Finally, the analysis can be expanded to compare the behavior of taxes and relative standards in addressing stock pollution problems. Nevertheless, the key insights of the model would probably hold. The approach taken here can be further tailored to the circumstances of specific sectors. Yet, derivation and comparison of dynamic implications of direct control and market-based instruments should not ignore that standards tend to become more stringent over time, as this has profound implications for the results obtained.

\section{APPENDIX}

\section{PROOFS}

\section{Proposition 1}

Total differentiation of (24) for $\dot{\bar{t}}(t)=0$, yields

$$
d \bar{t}=\frac{1}{J}\left\{m_{1}(\lambda) d \lambda-\alpha_{2} m_{1}(\psi) d \psi-\alpha_{3} m_{1}(\phi) d \phi+m_{2}(\phi) d \alpha_{1}-\left[m_{2}(\psi)-m_{2}(\phi)\right] d \alpha_{1}\right\},
$$

where

$$
\begin{gathered}
J=f_{1}(\lambda, \bar{t}) f_{2}(\lambda, \bar{t})-\alpha_{2} f_{1}(\psi, \bar{t}) f_{2}(\psi, \bar{t})-\alpha_{3} f_{1}(\phi, \bar{t}) f_{2}(\phi, \bar{t}), \\
m_{1}(a)=\frac{\partial f_{2}(a, \bar{t})}{\partial a}=\frac{e^{-(r-a) \bar{t}}}{1-e^{-(r-a) \bar{t}}}\left[\frac{\bar{t}(r-a)}{1-e^{-(r-a) t}}-1\right] \text { for } r>a=\lambda, \psi, \phi,
\end{gathered}
$$

and $m_{2}(a)=f_{2}(a, \bar{t})$. Also, from (25),

$$
d \lambda=\alpha_{2} d \psi+\alpha_{3} d \phi-d \eta-\phi d \alpha_{1}+(\psi-\phi) d \alpha_{2},
$$

and introducing it into (A1), yields

$$
\left[\begin{array}{c}
\frac{d \bar{t}(t)}{d \psi} \\
\frac{d \bar{t}(t)}{d \phi} \\
\frac{d \bar{t}(t)}{d \eta} \\
\frac{d \bar{t}(t)}{d \alpha_{1}} \\
\frac{d \bar{t}(t)}{d \alpha_{2}}
\end{array}\right]=\frac{1}{J}\left[\begin{array}{c}
-\alpha_{2}\left[m_{1}(\psi)-m_{1}(\lambda)\right] \\
-\alpha_{3}\left[m_{1}(\phi)-m_{1}(\lambda)\right] \\
-m_{1}(\lambda) \\
m_{2}(\phi)-\phi m_{1}(\lambda) \\
-\left[m_{2}(\psi)-m_{2}(\phi)\right]+\left[(\psi-\phi)-m_{1}(\lambda)\right]
\end{array}\right],
$$


where $J>0$, as optimal $\bar{t}$ need to verify (24) and the second-order condition ${ }^{29}$

$$
-f_{1}(\lambda, \bar{t}) f_{2}(\lambda, \bar{t})+\alpha_{2} f_{1}(\psi, \bar{t}) f_{2}(\psi, \bar{t})+\alpha_{3} f_{1}(\phi, \bar{t}) f_{2}(\phi, \bar{t})<0 .
$$

Differentiation of $m_{1}(a)$ then obtains

$$
\frac{\partial m_{1}(a)}{\partial a}=\frac{\left(2 e^{-\bar{t}(r-a)}+(r-a)\left(1+e^{-\bar{t}(r-a)}\right) \bar{t}-2\right) \bar{t}}{e^{(r-a) \bar{t}}\left(1-e^{-\bar{t}(r-a)}\right)^{3}}>0,
$$

as $g_{1}(\bar{t}, \cdot)=2 e^{-\bar{t}(r-a)}+(r-a)\left(1+e^{-\bar{t}(r-a)}\right) \bar{t}>2, \forall \bar{t}>0$, given that $g_{1}(0, \cdot)=2$ and

$$
\frac{\partial g_{1}(\bar{t}, \cdot)}{\partial \bar{t}}=-(r-a)\left[(1+(r-a) \bar{t}) e^{-\bar{t}(r-a)}-1\right]
$$

is positive if $g_{2}(\bar{t}, \cdot)=(1+(r-a) \bar{t}) e^{-\bar{t}(r-a)}<1$, which holds for $\bar{t}>0$ as $g_{2}(0, \cdot)=1$ and

$$
\frac{\partial g_{2}(\bar{t}, \cdot)}{\partial \bar{t}}=-\bar{t} e^{-\bar{t}(r-a)}(r-a)^{2}<0
$$

Finally, note that $m_{1}(a)>0$ if

$$
\frac{\bar{t}(r-a)}{\left(1-e^{-(r-a) \bar{t}}\right)}-1>0 \text { for } a<r .
$$

But this is true since

$$
\frac{\bar{t}(r-a)}{1-e^{-(r-a) \bar{t}}}-1=\int_{0}^{\bar{t}} \frac{(r-a)\left[1-e^{-(r-a) \tau}\right]}{1-e^{-(r-a) \bar{t}}} d \tau,
$$

for $a \leq r$, and $1>e^{-(r-a) \bar{t}}$ for $0 \leq \tau \leq \bar{t}, a \leq r$.

Equations (A4) and (A5), for $\lambda_{v}<\psi, \phi$, and the fact that $m_{1}(a)>0$, prove the proposition.

\section{Lemma 3}

Introducing $Z(t)=\bar{Z}$ and $\rho_{v 0}+\lambda_{v 0}-\phi=0$ into (37) and using l'Hôpital's rule yields

$$
\bar{Z}=X_{v 0}(0) \gamma_{v 0}(0) \bar{t}_{v 0} \rho_{0}\left[1-e^{-\rho_{v 0} \bar{t}_{v 0}}\right]^{-1},
$$

where $X_{v 0}, \gamma_{v 0}, \bar{t}_{v 0}$, and $\rho_{v 0}$ are values along a BGP with a constant pollution level. By introducing $\phi_{0}$ and the rate of price growth associated with $\phi_{0}$, that is,

29. Alternatively, note that introducing (21) into (6) yields $\pi(\bar{t})=\left\{[P(t)] /\left[f_{1}(\lambda, \bar{t})\right]\right\}-$ $\left\{[k(t)] / \alpha_{1}\right\}$ and $\partial \pi / \partial t=0$ yields (24), substituting (22), and the second-order condition $\partial^{2} \pi / \partial^{2} \bar{t}<0$ implies $J>0$, introducing (22). 


$$
\lambda_{v 0}=\psi \alpha_{2}+\phi_{0}\left(1-\alpha_{1}-\alpha_{2}\right)-\eta,
$$

into (24), the value of $\bar{t}_{v 0}$ is determined. To find $v_{v 0}(0)$ write $X_{v 0}(0)$ and $\gamma_{v 0}(0)$ as functions of $v_{v 0}(0)$. By (18),

$$
\gamma_{v 0}(0)=b_{3}\left(v_{v 0}(0)\right)^{-\left(\alpha_{1}+\alpha_{2}\right)},
$$

where

$$
b_{3}=\frac{\left[\alpha_{3} f_{1}\left(\phi_{v 0}, \bar{t}_{v 0}\right)\right]^{\left(\alpha_{1}+\alpha_{2}\right)}}{A \alpha_{1}^{\alpha_{1}}}\left[\frac{w(0)}{f_{1}\left(\psi, \bar{t}_{v 0}\right) \alpha_{2}}\right]^{\alpha_{2}} .
$$

By (29),

$$
X_{v 0}(0)=b_{4}\left(v_{v 0}(0)\right)^{-\mu a_{3}}
$$

where

$$
b_{4}=\left(A \alpha_{1}\right)^{\mu} B f_{1}\left(\lambda_{v 0}, \bar{t}\right)^{-\mu}\left[\frac{\alpha_{2}}{\alpha_{1}} \frac{f_{1}\left(\psi, \bar{t}_{v 0}\right)}{w(0)}\right]^{\mu \alpha_{2}}\left[\frac{\alpha_{3}}{\alpha_{1}} f_{1}\left(\phi_{0}, \bar{t}_{v 0}\right)\right]^{\mu \alpha_{3}} .
$$

Introducing (A8) and (A9) into (A7) yields (41).

\section{Proposition 5}

Rewrite (24) and (49), respectively, as

$$
\begin{aligned}
& \Psi_{1}(\bar{t}, \cdot)=\Psi_{2}(\bar{t}, \cdot), \\
& \Psi_{3}(\bar{t}, \cdot)=\Psi_{2}(\bar{t}, \cdot),
\end{aligned}
$$

with $\Psi_{1}(\bar{t}, \cdot)=f_{2}(\lambda, \bar{t})-\alpha_{3} f_{2}(\phi, \bar{t}), \quad \Psi_{2}(\bar{t}, \cdot)=\alpha_{2} f_{2}(\psi, \bar{t})$, and $\Psi_{3}(\bar{t}, \cdot)=\left(\alpha_{1}+\alpha_{2}\right)$ $f_{2}(\lambda, \bar{t})$.

The economic life of capital under taxes is given by (A10) and under DRS by (A11), taking into account that $\lambda_{v 0}=\lambda_{s 0}=\lambda_{0}$ and that $\lambda_{0}<\phi_{0}$ with $\rho_{0}>0$. As

$$
\frac{\partial f_{2}(a, \bar{t})}{\partial t}=-f_{1}(a, \bar{t}) f_{2}(a, \bar{t})<0,
$$

one knows that $\left(\partial \Psi_{2}\right) /(\partial \bar{t})<0$ and $\left(\partial \Psi_{3}\right) /(\partial \bar{t})<0$. Also, note that

$$
\frac{\partial\left(f_{1}(a, \bar{t}) f_{2}(a, \bar{t})\right)}{\partial a}=\frac{(r-a)\left(2 e^{-\bar{t}(r-a)}+(r-a)\left(1+e^{-\bar{t}(r-a)}\right) \bar{t}-2\right)}{e^{e^{\bar{t}(r-a)}}\left(1-e^{-\bar{t}(r-a)}\right)^{3}}>0,
$$

as $2 e^{-\bar{t}(r-a)}+(r-a)\left(1+e^{-\bar{t}(r-a)}\right) \bar{t}>2$ (see the appendix, sec. 1$)$. The definition of $J$, with $J>0$ (see the appendix, sec. 1 ), eq. (A12), and $\lambda_{0}<\phi_{0}$ obtains

$$
\left(1-\alpha_{3}\right) f_{1}\left(\lambda_{0}, \bar{t}\right) f_{2}\left(\lambda_{0}, \bar{t}\right)-\alpha_{2} f_{1}(\psi, \bar{t}) f_{2}(\psi, \bar{t})>J>0
$$


and hence

$$
\frac{\partial \Psi_{3}(\bar{t}, \cdot)}{\partial t}=-\left(\alpha_{1}+\alpha_{2}\right) f_{1}\left(\lambda_{0}, \bar{t}\right) f_{2}\left(\lambda_{0}, \bar{t}\right)<-\alpha_{2} f_{1}(\psi, \bar{t}) f_{2}(\psi, \bar{t})=\frac{\partial \Psi_{2}(\bar{t}, \cdot)}{\partial t}<0
$$

(i.e., $\Psi_{3}(\bar{t}, \cdot)$ decreases faster than $\Psi_{2}(\bar{t}, \cdot)$ with $\left.\bar{t}\right)$.

$J>0$ and $f_{1}(\psi, \bar{t}) f_{2}(\psi, \bar{t})>0$ also imply $f_{1}\left(\lambda_{0}, \bar{t}\right) f_{2}\left(\lambda_{0}, \bar{t}\right)>\alpha_{3} f_{1}\left(\phi_{0}, \bar{t}\right) f_{2}\left(\phi_{0}, \bar{t}\right)$ and thus

$$
\frac{\partial \Psi_{1}(\bar{t}, \cdot)}{\partial t}=-f_{1}\left(\lambda_{0}, \bar{t}\right) f_{2}\left(\lambda_{0}, \bar{t}\right)+\alpha_{3} f_{1}\left(\phi_{0}, \bar{t}\right) f_{2}\left(\phi_{0}, \bar{t}\right)<0
$$

In addition, $\left[\partial f_{2}(a, \bar{t})\right] /(\partial a)>0$ (see eqs. [A3] and [A6]) implies that $\Psi_{1}(\bar{t}, \cdot)<$ $\Psi_{3}(\bar{t}, \cdot) \forall \bar{t}$, as $f_{2}\left(\lambda_{0}, \bar{t}\right)<f_{2}\left(\phi_{0}, \bar{t}\right)$ yields $\Psi_{1}(\bar{t}, \cdot)<\left(1-\alpha_{3}\right) f_{2}\left(\lambda_{0}, \bar{t}\right)=\Psi_{3}(\bar{t}, \cdot)$. Finally, note that, with $\Psi_{2}(1, \cdot)>0$, to have an interior solution for DRS one needs $\Psi_{2}(1, \cdot)<\Psi_{3}(1, \cdot)$ (given $\left.\left[\left(\partial \Psi_{3}\right) /(\partial \bar{t})\right]<\left[\left(\partial \Psi_{2}\right) /(\partial \bar{t})\right]<0\right)$. Using these results and representing $\Psi_{1}(\bar{t}, \cdot), \Psi_{2}(\bar{t}, \cdot)$, and $\Psi_{3}(\bar{t}, \cdot)$ graphically with $\bar{t}$ on the $x$-axis, it is evident that $\Psi_{2}(\bar{t}, \cdot)$ crosses $\Psi_{1}(\bar{t}, \cdot)$ before crossing $\Psi_{3}(\bar{t}, \cdot)$. In other words, the graph is qualitatively always as in the example shown in figure A1. ${ }^{30}$

When $\rho_{0}=0$, one has $\lambda_{0}=\phi_{0}$ and thus $\Psi_{1}(\bar{t}, \cdot)=\Psi_{3}(\bar{t}, \cdot) \forall \bar{t}$. Thus, both functions cross $\Psi_{2}(\bar{t}, \cdot)$ at the same point.

\section{Proposition 6}

As the rate of output growth is equal under both policies $\left(\rho_{\mathrm{v} 0}=\rho_{s 0}=\rho_{0}\right)$ by proposition 4 , it is sufficient to find under what conditions the rate of output at time zero under DRS, $X_{s 0}(0)$, is greater than the rate of output at time zero under taxes, $X_{v 0}(0)$. From (A7) and an equation analogous to (A7) for DRS, use of $\rho_{0}=$ $\rho_{s 0}$ implies

$$
\frac{X_{v 0}(0)}{X_{s 0}(0)}=\frac{\bar{t}_{s 0}}{\bar{t}_{v 0}} \frac{1-e^{-\rho_{0} \bar{t}_{v 0}}}{1-e^{-\rho_{0} \bar{t}_{0}}} \frac{\gamma_{s 0}}{\gamma_{v 0}} .
$$

Introduce (45) into (50) and introduce into (22) an expression for $k(t)$ for taxes obtained introducing $\gamma_{0}$ and (21) into (1) and solving. Then, write both expressions for $t=0$ and divide one by the other one:

$$
\frac{P_{s 0}}{P_{v 0}}=\left(\alpha_{1}+\alpha_{2}\right) \frac{1-e^{-\left(r-\lambda_{0}\right) \bar{t}_{00}}}{1-e^{-\left(r-\lambda_{0}\right) \bar{t}_{00}}}\left(\frac{\gamma_{v 0}}{\gamma_{s 0}}\right)^{\alpha_{3} /\left(\alpha_{1}+\alpha_{2}\right)}\left(\frac{1-e^{-(r-\psi) \bar{t}_{0}}}{1-e^{-(r-\psi) \bar{t}_{0}}}\right)^{\alpha_{2} /\left(\alpha_{1}+\alpha_{2}\right)} .
$$

Using the demand equation $P_{s 0} / P_{v 0}=\left(X_{v 0}(0) / X_{s 0}(0)\right)^{1 / \mu}$ and substituting it and (A13) into (A14) yields

30. The figure was drawn for $\left(r, \psi, \alpha_{1}, \alpha_{2}, \eta, \delta, \mu\right)=(0.06,0.03,0.17,0.25,0.05,0.05$, 0.04 ), yielding $\bar{t}_{v 0}=43$ and $\bar{t}_{s 0}=59$. 


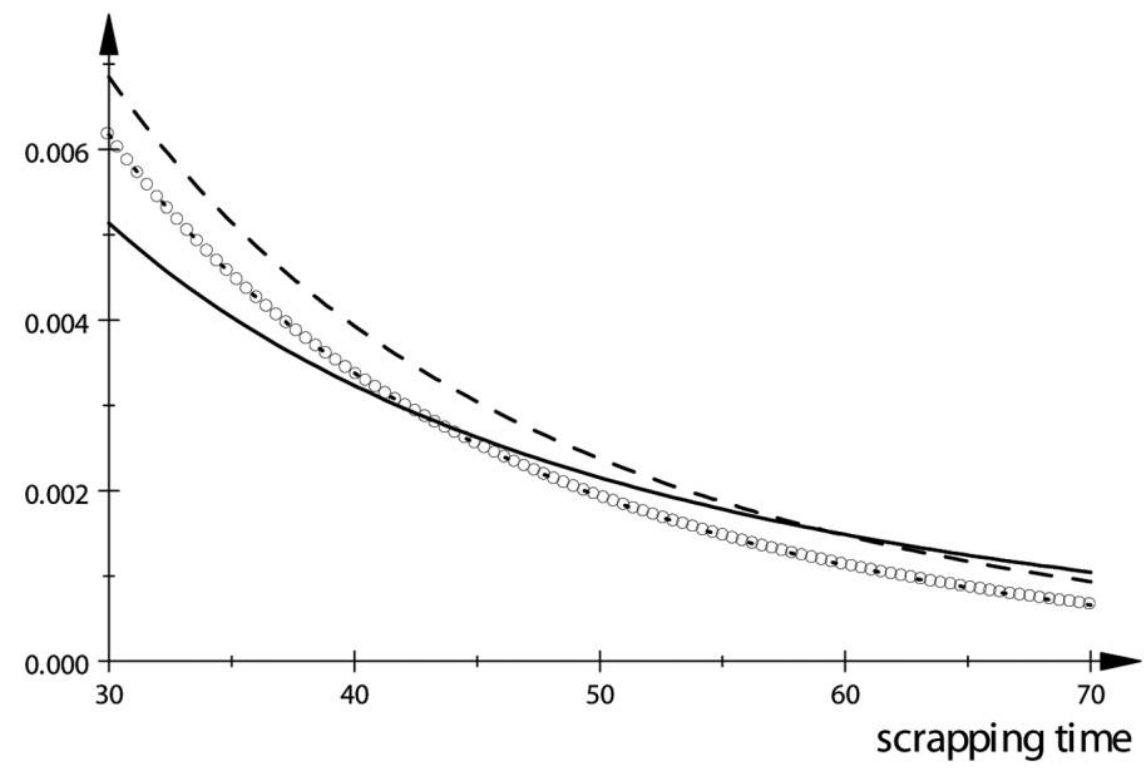

Figure A1. Scrapping time for taxes and DRS. $\Psi_{1}\left(\bar{t},{ }^{\cdot}\right)$ is the dotted line, $\Psi_{2}\left(\bar{t},{ }^{\cdot}\right)$ the solid line, and $\Psi_{3}(\bar{t}, \cdot)$ the dashed line.

$$
\begin{aligned}
& \left(\frac{X_{v 0}(0)}{X_{s 0}(0)}\right)^{(1 / \mu)+\left[\alpha_{3} /\left(\alpha_{1}+\alpha_{2}\right)\right]} \\
& =\frac{\left(\alpha_{1}+\alpha_{2}\right)\left(1-e^{-\left(r-\lambda_{0}\right) \bar{t}_{t_{0}}}\right)}{1-e^{-\left(r-\lambda_{0}\right) \bar{t}_{t_{0}}}}\left(\frac{\bar{t}_{s 0}}{\bar{t}_{v 0}} \frac{1-e^{-\rho_{0} \bar{t}_{10}}}{1-e^{-\rho_{0} \bar{t}_{0}}}\right)^{\alpha_{3} /\left(\alpha_{1}+\alpha_{2}\right)}\left(\frac{1-e^{-(r-\psi) \bar{t}_{0}}}{1-e^{-(r-\psi) \bar{t}_{00}}}\right)^{\alpha_{2} /\left(\alpha_{1}+\alpha_{2}\right)},
\end{aligned}
$$

and this expression is smaller than 1 if (63) holds.

To obtain the first sufficient condition recall that the proof of proposition 5 has shown that $\bar{t}_{v 0}=\bar{t}_{s 0}$ when $\rho_{0}=0$. In this case $f_{3}(a)=1$ and (63) simplifies to

$$
\left(\alpha_{1}+\alpha_{2}\right)^{\left(\alpha_{1}+\alpha_{2}\right) / \alpha_{3}}<1
$$

and this holds always.

To obtain (64) observe that the least favorable case for (63) is to have $f_{3}\left(\rho_{0}\right)=1$, $f_{3}\left(r-\lambda_{0}\right)=1$, and $f_{3}(r-\psi)=\bar{t}_{v 0} / \bar{t}_{s 0}$. With these values, (63) simplifies to (64).

\section{REFERENCES}

Averch, Harvey, and Leland L. Johnson. 1962. Behavior of the firm under regulatory constraint. American Economic Review 52, no. 5:1052-69.

Azomahou, Theophile T., Raouf Boucekkine, and Phu Nguyen-Van. 2009. Promoting clean technologies under imperfect competition. CORE Discussion Papers 2009011, Université Catholique de Louvain. 
Baumol, William J., and Wallace E. Oates. 1974. The theory of environmental policy. Englewood Cliffs, NJ: Prentice-Hall.

Berck, Peter, and Gloria E. Helfand. 2005. The case of markets versus standards for pollution policy. Natural Resources Journal 45:345-68.

Bliss, Christopher J. 1968. On putty-clay. Review of Economic Studies 35, no. 2:105-32.

. 2005. Introduction: The theory of capital; a personal overview. In Capital theory, vol. 1, ed.

C. Bliss, A. J. Cohen, and G. C. Harcourt. Cheltenham: Elgar.

Boucekkine, Raouf, Natali Hritonenko, and Yuri Yatsenko. 2008. Optimal firm behavior under environmental constraints. Discussion Paper 2008024, Université Catholique de Louvain.

Buchanan, James M., and Gordon Tullock. 1975. Polluters' profits and political response: Direct controls versus taxes. American Economic Review 65, no. 1:139-47.

Cohen, Avi J., and G. C. Harcourt. 2003. Whatever happened to the Cambridge capital theory controversies? Journal of Economic Perspectives 17, no. 1:199-214.

Downing, Paul B., and Lawrence J. White. 1986. Innovation in pollution control. Lournal of Environmental Economics and Management 13:18-29.

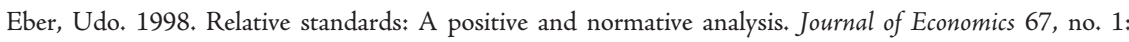
$17-38$.

Farzin, Y. H., K. J. M. Huisman, and P. M. Kort. 1998. Optimal timing of technology adoption, Iournal of Economic Dvnamics and Control 22:779-99.

Fischer, Carolyn. 2001. Rebating environmental policy revenues: Output-based allocations and tradable performance standards. RFF Discussion Paper 01-22, Resources for the Future, Washington, DC.

Fullerton, Don, and Garth Heutel. 2010. The general equilibrium incidence of environmental mandates. American Economic Journal: Economic Policy 2:64-89.

Goeschl, Timo, and Grischa Perino. 2007. Innovation without magic bullets: Stock pollution and R\&D sequences. Iournal of Environmental Economics and Management 54:146-61.

Hamilton, Stephen F., and Till Requate. 2012. Emissions standards and ambient environmental quality standards with stochastic environmental services. Iournal of Environmental Economics and Management 64:377-89.

Harford, Jon D. 1978. Firm behavior under imperfectly enforceable pollution standards and taxes. Lournal of Environmental Economics and Manasement 5:26-43.

Harford, Jon D., and S. Ogura. 1983. Pollution taxes and standards: A continuum of quasi-optimal solutions. Lournal of Environmental Economics and Management 10:1-17.

Hart, Rob. 2004. Growth, environment and innovation: A model with production vintages and environmentally oriented research. Lournal of Environmental Economics and Management 48:1078-98.

Helfand, Gloria E. 1991. Standards versus standards: The effects of different pollution restrictions. American Economic Review 81, no. 3:622-34.

Heutel, Garth. 2011. Plant vintages, grandfathering, and environmental policy. Journal of Environmental Economics and Management 61:36-51.

Hjalmarsson, Lennart. 1974. The size distribution of establishments and firms derived from an optimal process of capacity expansion. European Economic Review 5:123-40.

Hochman, Eithan, and David Zilberman. 1978. Examination of environmental policies using production and pollution microparameter distributions. Econometrica 46, no. 4:739-60. 
Holland, Stephen P. 2012. Emissions taxes versus intensity standards: Second-best environmental policies with incomplete regulation. Iournal of Environmental Economics and Management 63:375-87.

Holland, Stephen P., Jonathan E. Hughes, and Christopher R. Knittel. 2009. Greenhouse gas reductions under low carbon fuel standards? American Economic Journal: Economic Policy 1:106-46.

Hritonenko, Natali, and Yuri Yatsenko. 2008. Anticipation echoes in vintage capital models. Mathematical and Computer Modeling 48:734-48.

Huang, Haixiao, Madhu Khanna, Hayri Önal, and Xiaoguang Chen. 2012. Stocking low carbon policies on the renewable fuels standards: Economic and greenhouse gas implications. Energy Policy 56:5-15.

Jaffe, Adam B., and Robert N. Stavins. 1995. Dynamic incentives of environmental regulations: The effects of alternative policy instruments on technology diffusion. Journal of Environmental Economics and Management 29: S43-S63.

Johansen, Leif. 1959. Substitution versus fixed production coefficients in the theory of economic growth: A synthesis. Econometrica 27, no. 2:157-76.

- 1965. Public economics. Chicago: North-Holland.

. 1972. Production functions: An integration of micro and macro, short run and long run aspects. Chicago: North-Holland.

Jung, Chulho, Kerry Krutilla, and Roy Boyd. 1996. Incentives for advanced pollution abatement technology at the industry level: An evaluation of policy alternatives. Iournal of Environmental Economics and Management 30:95-111.

Lahiri, Sajal, and Yoshiyasu Ono. 2007. Relative emission standard versus tax under oligopoly: The role of free entry. Journal of Economics 91, no. 2:107-28.

Milliman, Scott R., and Raymond Prince. 1989. Firm incentives to promote technological change in pollution control. Iournal of Environmental Economics and Management 17:247-65.

Mohr, Robert D. 2006. Environmental performance standards and the adoption of technology. Ecological Economics 58:238-48.

Montero, Juan-Pablo. 2002. Permits, standards, and technology innovation. Iournal of Environmental Economics and Management 44:23-44.

Requate, Till. 2005. Dynamic incentives by environmental policy instruments: A survey. Ecological Economics 54:175-95.

Requate, Till, and Wolfram Unold. 2003. Environmental policy incentives to adopt advanced abatement technology: Will the true ranking please stand up? European Economic Review 47:125-46.

Ricci, Francesco. 2007. Environmental policy and growth when inputs are differentiated in pollution intensity. Environmental and Resource Economics 38:285-310.

Salter, W. E. G. 1966. Productivity and technical change. 2nd ed. Cambridge: Cambridge University Press.

Smulders, Sjak, and Amos Zemel. 2011. Tales of energy transitions. Presented at the EAERE 2011 Conference, Rome, June 29-July 2.

Stavins, Robert N. 2006. Vintage-differentiated environmental regulation. Stanford Environmental Law Journal 25:29-63.

Stokey, Nancy L. 1998. Are there limits to growth? International Economic Review 39, no. 1:1-31.

Xabadia, Àngels, Renan U. Goetz, and David Zilberman. 2006. Control of accumulating stock pollution by heterogeneous producers. Journal of Economic Dynamics and Control 30, no. 7:1105-30.

Weitzman, Martin L. 1974. Prices vs. quantities. Review of Economic Studies 41, no. 4:477-91. 
Wing, Ian Sue, A. Denny Ellerman, and Jaemin Song. 2006. Absolute vs. intensity limits for $\mathrm{CO}_{2}$ emission control: Performance under uncertainty. MIT Joint Program on the Science and Policy of Global Change, Report No. 130. MIT, Cambridge, MA.

Zerbe, Richard O. 1970. Theoretical efficiency in pollution control. Economic Inquiry 8, no. 4:364-76.

Zilberman, David, Jinhua Zhao, and Amir Heiman. 2012. Adoption versus adaptation, with emphasis on climate change. Annual Review of Resource Economics 4, no. 1:27-53. 